\title{
Towards an electronic national injury surveillance system in Saudi Arabia
}

\author{
F. Alanazi, ${ }^{1}$ S.A. Hussain, ${ }^{7}$ A. Mandil' ${ }^{2}$ and N. Alamro ${ }^{2}$
}

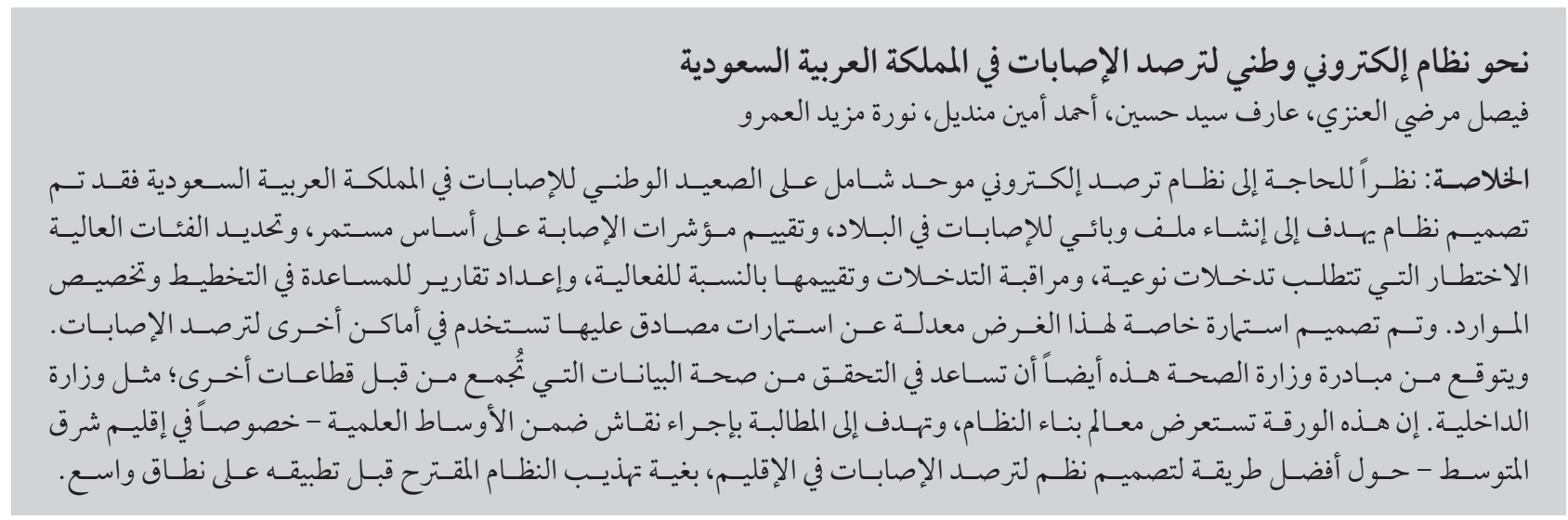

ABSTRACT Given the need for a uniform, comprehensive, electronic nationwide surveillance system for injuries in Saudi Arabia, a system was designed with the objectives of establishing an epidemiologic profile of injuries in the country; evaluating injury indicators on an ongoing basis; identifying high-risk groups requiring specific interventions; monitoring and evaluating interventions for effectiveness; and producing reports to assist in planning and resource allocation. A special form for this purpose was designed, modified from validated forms used elsewhere for injury surveillance. This initiative of the Ministry of Health is also expected to help validate data collected by other sectors, such as the Ministry of Interior. This paper reviews the milestones of building the system and aims to prompt a debate within the scientific community, especially within the Eastern Mediterranean Region, about the best way to design injury surveillance systems for the Region in order to fine-tune the proposed system before its full-scale implementation.

\section{Vers un système électronique national surveillance des traumatismes en Arabie saoudite}

RÉSUMÉ Compte tenu de la nécessité d'établir un système électronique pour la surveillance des traumatismes au plan national en Arabie saoudite qui soit exhaustif et uniforme, un système a été élaboré pour définir le profil épidémiologique des traumatismes dans le pays, évaluer les indicateurs de traumatismes de manière systématique, identifier les groupes à haut risque nécessitant des interventions spécifiques, surveiller les interventions et évaluer leur efficacité, et établir des rapports facilitant la planification et l'allocation des ressources. Un formulaire spécifique a été conçu, inspiré des formulaires validés déjà utilisés ailleurs pour la surveillance des traumatismes. Cette initiative du ministère de la Santé devrait également permettre de valider les données recueillies par d'autres secteurs, tels que le ministère de l'Intérieur. Le présent article examine non seulement les étapes de développement de ce système, mais vise aussi à susciter un débat au sein de la communauté scientifique, notamment dans la Région de la Méditerranée orientale, sur la meilleure façon de mettre au point des systèmes de surveillance des traumatismes pour la Région afin d'améliorer le système proposé avant sa mise en œuvre à grande échelle.

'Injuries and Accidents Prevention Programme, Ministry of Health, Riyadh, Saudi Arabia (Correspondence to F. Alanazi: ksainjury@hotmail.com). ${ }^{2}$ Department of Family and Community Medicine, College of Medicine, King Saud University, Riyadh, Saudi Arabia.

Received: 01/07/13; accepted: 26/11/14 


\section{Introduction}

Injuries account for at least $9 \%$ of the global burden of mortality and are a threat to health in every country of the world. For every death it is estimated that there are dozens of hospitalizations, hundreds of emergency department visits and thousands of doctors' appointments. A large proportion of people surviving their injuries incur temporary or permanent disabilities. Although injuries and violence are health threats in every country, the pattern and extent of different injuries varies from country to country (1).

According to the World Health Organization (WHO), injuries account for $11.3 \%$ of total deaths in the Eastern Mediterranean Region (EMR) (2). In Saudi Arabia the Ministry of Health $(\mathrm{MoH})$ reported in 2010 that injuries represent the second cause of death in MoH hospitals, accounting for $19.2 \%$ of all causes of death. There were 2006907 injury-related visits to $\mathrm{MoH}$ hospitals and 563051 to primary-care centres in 2010 (3). A conservative estimate of the annual cost of road traffic accidents in the country is 21 billion Saudi riyals (4). Local studies have been carried out in Saudi Arabia on several types of injuries, including burns (5-7), drowning (8) and gunshots (9); none have been carried out on a regional or national scale. Violence too has been sporadically reported in the literature on Saudi Arabia. A retrospective study at the Forensic Medicine Centre in Dammam, Saudi Arabia during 2002-06 showed 64 fatalities from gunshot injuries: 55 homicides, 7 suicides and 2 accidental shootings (10). Child abuse and neglect were presented in a retrospective collection of data on all children evaluated by the suspected child abuse and neglect (SCAN) team in King Abdulaziz Medical City for the National Guard from 2000 to 2008 (11).

Reports on injuries and violence have therefore generally been smallscale and in isolated settings, only indicating what we consider the tip of the iceberg of the morbidity and mortality burden of injuries in Saudi Arabia. A complete picture of the situation in the country is required for efficient planning and implementation of effective interventions.

\section{Injury surveillance systems: a global perspective}

There are many injury surveillance systems and databases around the world. All of them include unintentional injuries and some include intentional ones as well, while rarely they concentrate on specific types of injuries only. Some examples are provided below.

The United States Consumer Product Safety Commission's national electronic injury surveillance system (NEISS) is a national probability sample of hospitals in the US and its territories. The Canadian hospitals injury reporting and prevention program (CHIRPP) was established as an emergency-room based injury surveillance system that operates in 10 paediatric and 6 general hospitals (12). In Australia, the injury surveillance information system (ISIS) was designed, developed and piloted by the national injury surveillance and prevention program (13), with other examples in place as well (14-16). The United Kingdom's home/leisure accident surveillance system (HASS/ LASS) is a national injury surveillance system that reports on home injuries among all ages since 1978 (17). The Dutch injury surveillance system (LIS) is run by the Consumer Safety Institute at emergency departments of a subset of Dutch hospitals and reports all types of injuries among all ages (18). Greece also has the emergency department injury surveillance system (EDISS) that covers all injury types in all ages (19). All the above surveillance systems share the fact that they are emergencydepartment based on a national level. On a regional level, the European home and leisure accident surveillance system (EHLASS) is a Europe-wide system that reports home injuries among all ages (20).

In the EMR, different agencies record data on injuries in most countries. Notable sources are hospitals, the police and other health-related agencies such as universities. Many EMR countries possess a health information system which records information such as deaths and other health statistics. The Egyptian injury surveillance system was implemented back in 1999. The system is decentralized and injuries are reported by the relevant facilities (hospitals, health centres, health groups and health units) (21). According to $\mathrm{WHO}$, the major impediment in collating data from different sources is the lack of coordination among the concerned sectors, which substantiates the argument that a uniform injury surveillance system should be in place to capture the occurrence of injuries at each level, regardless of which agency takes responsibility to set up the surveillance system.

\section{Background to the EISS}

Recognizing the burden of injuries in Saudi Arabia, the MoH launched the injury and accident prevention programme (IAPP) based in the NonCommunicable Disease Directorate of $\mathrm{MoH}$. The programme is mandated to establish and maintain an efficient and effective injury surveillance system; prepare the national annual injury report; provide assistance to the government in devising and reviewing policies and strategies for injury prevention; operate campaigns to educate the community at all levels about the high burden of injuries in the country; and develop the capacities of medical professionals in injury prevention and control. Under such a programme, an electronic national injury surveillance system (EISS) is currently being built, which is designed (in its initial phases) to be comprehensive, covering both 
non-intentional and intentional injuries diagnosed and managed at $\mathrm{MoH}$ facilities. Detailed information on the system is available in the $\mathrm{MoH}$ document prepared for this purpose (22).

The paper reviews the milestones of building the electronic facility-based injury surveillance system and is shared with the objective of starting a debate within the scientific community, especially in the EMR, about the best methods to be applied in the Region, to critique our methods and fine-tune the proposed system before its implementation phase.

\section{Objectives of the EISS}

Given that the current surveillance systems in Saudi Arabia are fragmented, do not capture the whole range of injuries and suffer from frequent under-reporting, a need was identified for a uniform nationwide surveillance system for injuries. A simple and practical EISS has therefore been designed to address these issues. The objectives of the EISS are to: establish the epidemiological profile of injuries in Saudi Arabia (evaluate the magnitude, burden, incidence and characteristics of specific injuries); compute and evaluate the indicators for injuries on an ongoing basis; identify high-risk groups requiringspecificinterventions; monitor and evaluate interventions for effectiveness; and produce reports on a periodic basis (annually and quarterly) that will help in planning and resource allocation at the national, regional and facility levels.

\section{Building the EISS}

Building the EISS passed through several phases, as outlined below.

\section{Acquiring the political will}

First and foremost, the political will and approval to establish the system was obtained at the highest levels in Saudi Arabia, both at the Council of Ministers and the MoH. This included preparation of policy briefs and presentations by the IAPP to the forums and clarifying the queries with convincing arguments to secure the final approvals. A high-profile visit of a team from the WHO Regional Office for the Eastern Mediterranean and from WHO Headquarters also paved the way towards the final agreement of the senior management in $\mathrm{MoH}$.

\section{Formation of expert teams}

A team of experts was constituted that comprised public health specialists and consultants from within and outside $\mathrm{MoH}$. The team interacted closely during the whole process and built consensus for all the steps.

\section{Preparation of background documents}

The team prepared the necessary documents, especially the background document of the IAPP (22) as well as the EISS. The document outlined the steps to be taken in the formalization of the system within the country, taking it through the different phases. An operations manual was prepared delineating the operational details of the process (23).

\section{Preparation and formalization of the EISS tool}

The team of experts prepared the initial draft of the EISS tool, taking inputs from the Injury surveillance guidelines of WHO and the US Centers for Disease Control and Prevention (24), the International classification of external causes of injury (ICECI) (25) and other international injury surveillance formats. A series of workshops and consultations were held in order to refine the tool, whereby stakeholders from outside the health sector were involved to get their inputs. The tool was formally endorsed by the higher level National Committee of the $\mathrm{MoH}$.

\section{Planning for the pilot of the surveillance system}

Data collection was planned to take place through 2 phases: an initial phase during the first year of operation (2013-14), which is considered a multi-centre pilot phase (involving 10 regions), and a second phase during subsequent years, which is expected to be nationwide (involving all 20 of Saudi Arabia's health regions), and to build on the results and lessons learned from the pilot phase.

\section{Training for the pilot phase}

Physicians and nurses were trained from these facilities for a period of 2-3 days each to start the data collection. The pilot phase is in progress and the results will be shared after its completion.

\section{Design of the EISS}

The EISS is an integrated nationwide system for ongoing, systematic collection, analysis and interpretation of injury-related data across Saudi Arabia that is essential for the planning, implementation and evaluation of interventions, closely integrated with the timely dissemination of these data to different stakeholders, including decision and policy-makers, health-care delivery institutions, health professionals, international agencies and the general public.

\section{Components of the EISS}

The EISS includes the following components (Figure 1).

- Sensors: actual surveillance reporters/data collectors who identify injuries and report them. These include emergency and trauma physicians and nurses at peripheral hospitals and primaryhealth-care centres (PHCC), in different health regions of Saudi Arabia.

- Reference signal (sensor report): the report of the above-mentioned reporters/data collectors. 


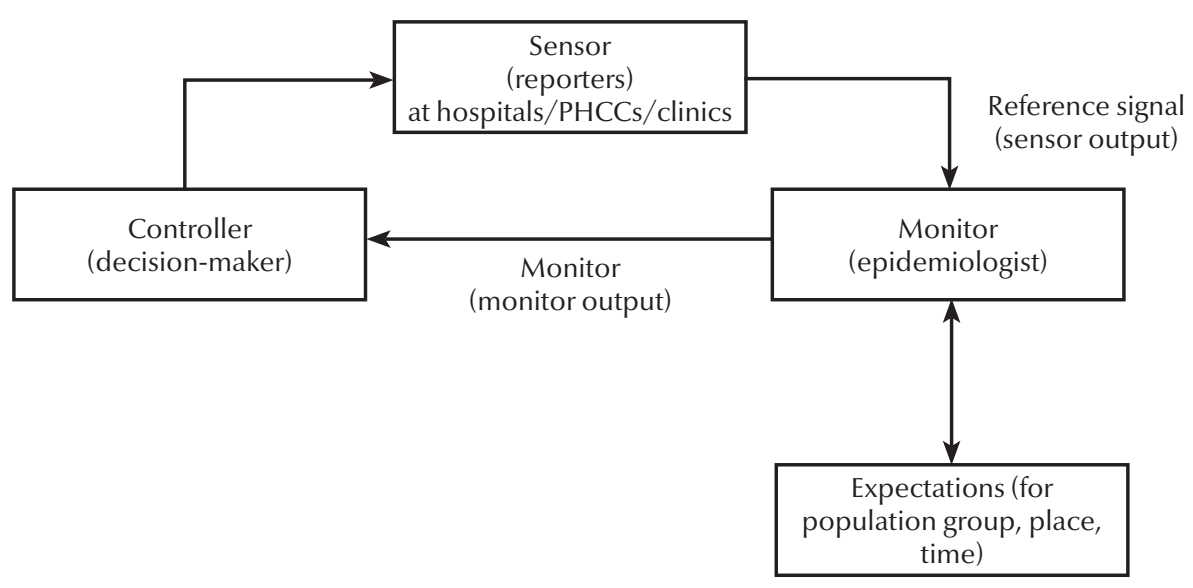

Figure 1 Components of the electronic injury surveillance system in Saudi Arabia

- Monitor and expectations: compares the reference signal (sensor report) with expectations. This is usually carried out by epidemiologists and biostatisticians at the central level, who compare the injury occurrences with prior expectations (threshold of concern) for the population group, place and time-period and produce their own report.

- Monitor signal: report (output) of the monitor which measures the difference between the reference sig$\mathrm{nal} /$ sensor reports and expectations, in order to assist in evidence-based decision- and policy-making.

- Controller: decision- or policy-makers who take corrective action aimed at handling the monitor signal, i.e. initiating prevention and control activities. This might be the district health officer regionally or the chief medical officer (e.g. $\mathrm{MoH}$ ) if a national decision is needed, as applies here to injury control activities.

\section{Surveillance team}

The EISS team includes the following: the $\mathrm{MoH}$ core team (central team at IAPP in Riyadh); regional coordinators (in the 20 health regions); health facility coordinators; sensors (data collectors in each health facility); monitors (epidemiologists and biostatisticians at the central level): controllers (policy- and decision-makers at the regional and national levels); and scientific committee members. Figure 2 illustrates the flow of data in the proposed surveillance system.

\section{Operations manual}

A detailed manual has been formulated and compiled by the core team and consultants to be distributed to each sensor (data collector), monitor and coordinator (regional/facility) in order to elaborate on concepts and types of surveillance; highlight the importance and objectives of the EISS; explain the components of the EISS and sampling procedures; emphasize the job descriptions of each component of the system; provide detailed description of the 2 sections of the EISS data collection tool with relevant examples; and introduce EISS expected outcomes. It therefore will act as an independent resource of information for all EISS personnel.

The EISS is considered to be a passive surveillance system, based on intensive training of staff to ensure understanding of the operations manual of the system; a form for data collection and standardization of operations; supervised data collection and production; related incentives at the health facility, regional and national levels; review of collected data at the regional and central levels; controller decisions built on surveillance data; and feedback to sensors (reporters) on a periodic basis.

Moreover, the EISS is considered to be sentinel surveillance, as data collection will take place from selected sentinel sites, in the form of randomly selected hospitals and PHCC that are expected to receive, manage and report injuries accordingly.

\section{Data collection}

\section{Data collection form}

A special form has been designed, as a modified version of several validated forms previously used for injury surveillance $(24,25)$. The form includes 2 main sections:

- Part 1: General information: health facility code (to be provided by the $\mathrm{MoH}$ core team); injury information (date, time, place, intent, nature, mechanism, site, severity); and injured-related personal information (national ID, sex, age, pregnancy [if female], occupation, education, driving under the influence of a substance, mode of arrival, disposition).

- Part 2: Information on the specific type of injury: e.g. road traffic injury (place of injury, injured person, type of vehicle, helmet use, reasons for accident, vehicle condition, climate, driver's characteristics, road characteristics); falls; burns; drown- 


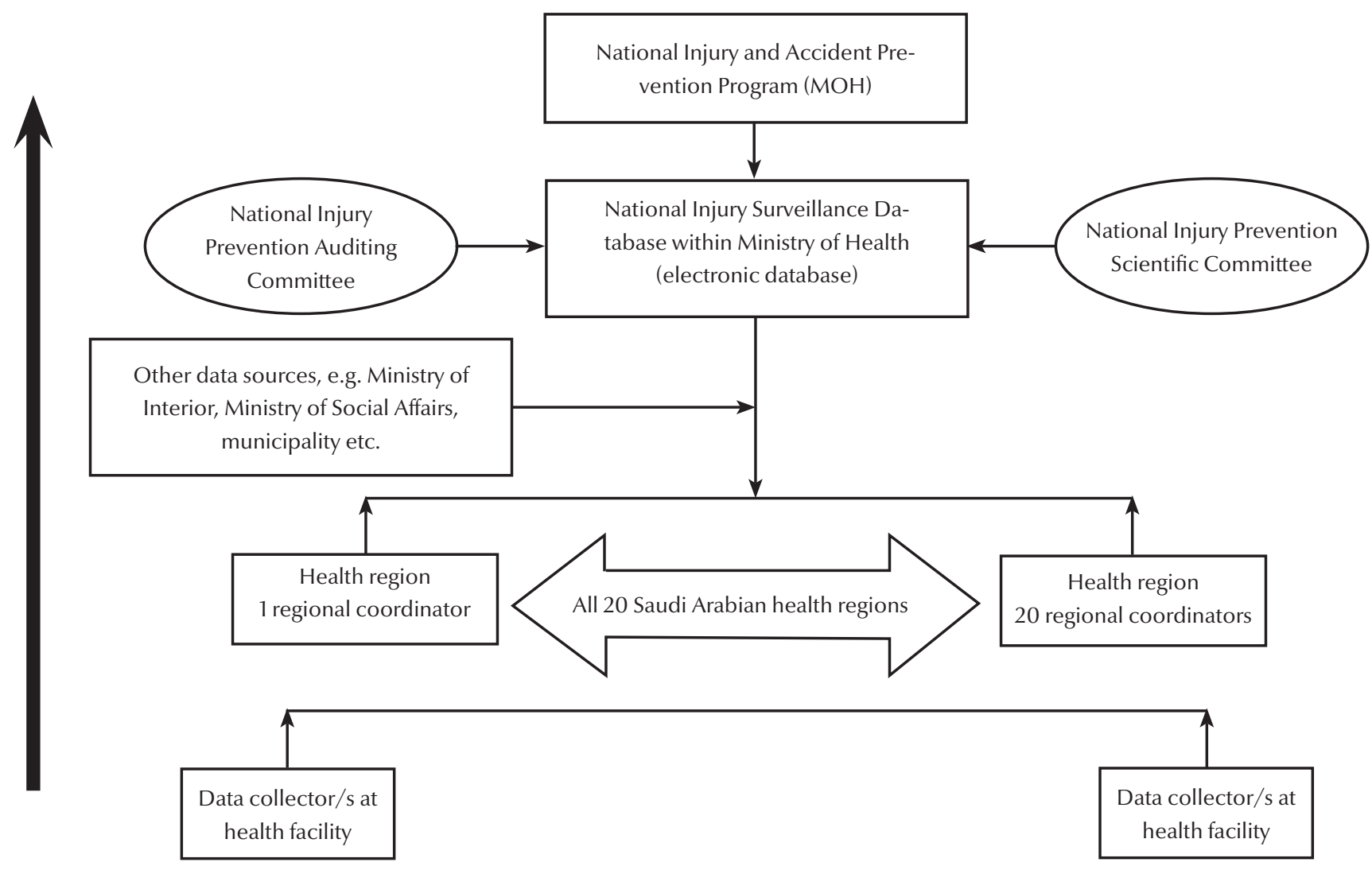

Figure 2 Flow of data during the surveillance process in the electronic injury surveillance system in Saudi Arabia

ing; violent injury (type, method); sports injury (type, contact with others); poisoning (type, mode). Also includes: additional information the respondent wishes to add, not requested by the data collection tool; data collector's code (to be provided by the $\mathrm{MoH}$ core team); date and time of completing the form.

\section{Data collection phases}

The data collection will be taking place in 2 main phases: a pilot phase and a nationwide phase. The pilot phase will involve a multi-stage stratified random sampling technique, as follows. From each of Saudi Arabia's geographical areas (eastern, northern, western, southern and central) 1 densely populated and 1 less populated health region will be selected (10 in total). This aims at recognizing variations, especially environmental, in terms of culture, climate, transportation facilities, roads, etc. during the pilot phase, which need to be addressed before implementing the system on a larger scale. For the pilot phase a total of 14 health facilities will be selected from each health region as follows: $3 \mathrm{MoH}$ hospitals; 5 PHCC; 1 governmental non-MOH hospital; 1 university hospital; and 1 private hospital; 3 private clinics. These initial sentinel sites will be gradually scaled up in a phased manner.

The nationwide stage will involve all health regions of Saudi Arabia, including hospitals and PHCC, whether belonging to $\mathrm{MoH}$ or other health-care agencies, with tertiary-care facilities included.

\section{The electronic system}

After design and review of the data collection form, it was transformed into a user-friendly electronic data entry form. It was designed to be used at all levels of the surveillance system. Thus, data collectors at the periphery in hospitals and PHCC will complete and submit the form online, to be reviewed by both the site coordinator and regional coordinator for completeness and accuracy, and edited accordingly. This will form the regional database, which will remain available for regional data management if needed. Thus, regional and local tables and statistics can be produced. After this process, forms will be transmitted to the central offices in Riyadh. All forms received at the central office will be subject to final review before inclusion in the national database. Data management processes include coding, entry, cleaning, analysis and interpretation. Periodic reports are to be produced on an annual or quarterly basis or even sooner as needed. This system also allows real-time information on a regional and national basis, as data are collected for central follow-up in Riyadh, which provides the profile of injuries by class, type, cause and outcome. 


\section{Expected outcomes}

The EISS is expected to provide comprehensive information on the injury situation in the country including information on the extent and nature of injuries. This information will help planners to allocate resources so as to achieve the greatest impact in preventing injuries, reducing the harm they may inflict, and treating and re-habilitating injured persons. Translated into reports, it is hoped that such data would provide the basis for strategic prevention and control policies and programmes. Specifically, the EISS is expected to provide the necessary national information about:

- epidemiological profile of injuries in Saudi Arabia (magnitude of the problem by type, site, nature and severity of injury, characteristics of specific injuries);
- high-risk populations for injuries (i.e. which kind of people are most likely to incur each type of injury), requiring specific prevention interventions;

- risk factors for injuries (i.e. which exposures contribute to or are associated with which type of injury);

- time trends of injuries in the country (i.e. whether a particular type of injury occurs more or less frequently, and is doing more or less harm);

- periodic calculation of selected injury indicators;

- comparison with data collected by other sectors (e.g. Ministry of Interior);

- identification of priorities for an injury prevention and control programme for decision and policy-makers, which allows needs-based and sound resource allocation;

- assessment of the cost-effectiveness of different implemented interventions;
- further behavioural research that would provide an insight for future interventions targeting injury prevention practices.

As a unique and innovative system for injury surveillance in Saudi Arabia, we expect such a system to be integrated with other existing and relevant surveillance systems, such as those of the $\mathrm{MoH}$ (noncommunicable diseases), the Ministry of Interior (police systems) and other health-care delivery agencies' systems. We expect the information generated to assist in sound policy- and decision-making for prevention and control of injuries in Saudi Arabia and thus to have an impact on the national development plans of the country. Moreover, we expect the system, once it is in action, to be a role model for the establishment of similar systems in neighbouring nations in the EMR and abroad.

\section{References}

1. New publications show injuries kill more than five million people a year. Press release, 13 May 2003 [Internet]. Geneva: World Health Organization; 2003 (http://www.who.int/ mediacentre/news/releases/2003/pr40/en/, accessed 26 December 2014).

2. The global burden of diseases. Geneva: World Health Organization; 2004.

3. Annual statistical report-1431. Riyadh, Saudi Arabia: Ministry of Health; 2010.

4. Al-Naami MY, Arafah MA, Al-Ibrahim FS. Trauma care systems in Saudi Arabia: an agenda for action. Ann Saudi Med. 2010 Jan-Feb;30(1):50-8. PMID:20103958

5. Al-Shlash S, Warnasuriya ND, Al Shareef Z, Filobbos P, Sarkans E. Al- Dusari S. Eight years experience of a regional burns unit in Saudi Arabia: Clinical and epidemiological aspects. Burns. Burns. 1996;22(5):376-80.

6. Pitkanen J, Al-Qattan MM. Epidemiology of domestic chemical burns in Saudi Arabia. Burns. 2001 Jun;27(4):376-8. PMID:11348747

7. Al-Qattan MM. Campfire burns of the palms in crawling infants in Saudi Arabia: results following release and graft of contractures. J Burn Care Res. 2009 Jul-Aug;30(4):616-9. PMID:19506489

8. Hijazi OM, Shahin AA, Haidar NA, Sarwi MF, Musawa ES. Effect of submersion injury on water safety practice after the event in children, Saudi Arabia. Saudi Med J. 2007 Jan;28(1):100-4. PMID:17206299

9. Softah AL, Eid Zahrani M, Osinowo O. Gunshot injuries in adults in the Abha region of Saudi Arabia. Afr J Med Med Sci. 2002 Mar;31(1):41-4. PMID:12518928

10. Al Madni O, Kharosha MA, Shotar AM. Firearm fatalities in Dammam, Saudi Arabia. Med Sci Law. 2008 Jul;48(3):237-40. PMID:18754211
11. Al Eissa M, Almuneef M. Child abuse and neglect in Saudi Arabia: journey of recognition to implementation of national prevention strategies. Child Abuse Negl. 2010 Jan;34(1):28-33. PMID:20092895

12. Mackenzie SG, Pless IB. CHIRPP: Canada's principal injury surveillance program. Canadian Hospitals Injury Reporting and Prevention Program. Inj Prev. 1999 Sep;5(3):208-13. PMID:10518269

13. Vimpani G, Hartley P. National injury surveillance and prevention project: final report. Canberra: Australian Government Publishing Service; 1991.

14. Harrison J, Tyson D. Injury surveillance in Australia. Acta Paediatr Jpn. 1993 Jun;35(3):171-8. PMID:8351982

15. McClure RJ, Burnside J. The Australian Capital Territory Injury Surveillance and Prevention Project. Acad Emerg Med. 1995 Jun;2(6):529-34. PMID:7497056

16. Hazard. Quarterly Bulletin of the Victorian Injury Surveillance System. Melbourne: Monash University Accident Research Centre; 1999.

17. Home Accident Surveillance System/Leisure Accident Surveillance System reports. London: Consumer Safety Unit, Department of Trade and Industry; 1995.

18. Letsel Informatie Systeem (LIS) Fact sheet 2004. Amsterdam: Consumer Safety Institute; 2004.

19. Petridou E, Simou E, Skondras C, Pistevos G, Lagos P, Papoutsakis G. Hazards of baby walkers in a European context. Inj Prev. 1996 Jun;2(2):118-20. PMID:9346073

20. Rogmans WHJ, Mulder S. European home and leisure accident surveillance system: evaluation of activities undertaken in the frame of the EC demonstration project. Amsterdam: Consumer Safety Unit; 1990.

21. Injury prevention and control. A guide to developing a multisectoral plan of action, surveillance and research. Cairo: World 
Health Organization Regional Office for the Eastern Mediterranean; 2006 (WHO-EM/HLP/033/E).

22. Hussain A, Al-Anzy F. National Injuries Surveillance System in Saudi Arabia. Riyadh: Ministry of Health, Injuries and Accidents Prevention Program; 2011.

23. Al-Anzy F, Mandil A, Al-Amro N, Hussain A. National electronic injuries surveillance system in Saudi Arabia: operations manual. Ministry of Health, Injuries and Accidents Prevention Program, 2012.

24. Injury surveillance guidelines. Geneva: World Health Organization; 2004 (WHO/NMH/VIP/1.02).

25. The International Classification of External Causes of Injury (ICECI). Geneva: World Health Organization; 2003. 